\title{
AGILE APPROACH FOR E-LEARNING IN DIGITAL-LEADERSHIP TRAINING FOR SMALL AND MEDIUM ENTERPRISES
}

\author{
Roger Hage, Helena Lovasz-Bukvova, Matej Hopp, Marvin Hölzl, Gerhard Kormann- \\ Hainzl, Michael Reiner, Deepak Dhungana, IMC University of Applied Sciences Krems,
} Austria

\section{Abstract}

Training for small and medium enterprises, especially in the context of leadership and digitalisation, has been traditionally carried out in form of presence workshops. Like other learning and training offers, this type of training needed to be carried out virtually during the COVID-19 pandemic, bringing advantages as well as disadvantages. Furthermore, the purpose of such courses is typically to convey a curriculum of preselected content and skills previously deemed useful. This paper presents the experiences from a mini-course on digital leadership carried out virtually during the pandemic that aims to incorporate SME needs in an agile manner. The presented mini-course is being developed using action research approach and aims to provide input for designing training in this context beyond the current crisis. The findings show high acceptance by the participants for the 100\% virtual format and the effectiveness of the pilot run was proven to increase the digital skills of the participants. Engaging participants in order to reflect their needs has proven challenging and will be considered in the next action iteration.

\section{Introduction}

In context of training for small and medium enterprises (SME), the learning format represents an important success factor, with flexibility and informality (both supporting responsiveness to the needs of the SME trainees) playing a key role. Responsiveness in teaching has been approached from the point of view of personalisation, but also using agile methods. Finally, increased flexibility has also been connected to virtual learning (due to its time and place independence).

SME represent a heterogeneous and varied target group, with structural difference and very different needs than larger enterprises (Ates et al., 2013). They are known to struggle to adapt to innovation and market changes, possibly due to their short-term focus and reactive behaviour (Ates et al., 2013). At the same time, they play a vital role in the 
economy; hence additional support, e.g. training programmes, is often directed at SME. According to Johnston and Loader (2003), successful SME training must provide a suitable cost-benefit ratio, target SME-specific skills, be flexible and accommodating, have an informal setting, and be well publicised. Besides influencing the absolute participation, the format of SME training can also lead to participation biases (often self-section biases), such as favouring younger, educated, or anyway growth-oriented SME managers (Bager et al., 2015). Finally, Jones et al. (2013) also connect training format with the resulting impact (business performance). Overall, the format and structure of SME training plays an important role in the effectivity of the training - selecting and preparing the "right" content is not sufficient.

Responsiveness, adaptability, and agility have recently become prized attributes not only in educational context ("agility" has been very popular to the point of overuse). In teaching, especially in context of corporate training, the ability to respond to learners' needs and adapt the learning process is a subject of long-standing research (e.g. Li \& Wong, 2019). Here too, the agile approach has been considered (e.g. Parsons \& MacCallum, 2019). Unlike personalised learning, which implies adaptation to individual needs of each participant (Prain et al., 2012), the use of agile methods is focused towards identifying and responding to the needs of the current learners as a group. In SME training, responsiveness and agility can be useful to meet the needs of the heterogeneous target group.

Providing training in a virtual format was not a new topic before the pandemic, many authors having already researched the relative advantages and disadvantages of virtual learning (see Table 1). While Jones et al. (2013) deem e-learning to be acceptable and effective in SME training, traditionally, management training in Austria is delivered in a face-to-face format. In context of the pandemic, however, this option was not available.

Table 1: $\quad$ Advantages and disadvantages of virtual learning (Dumford \& Miller, 2018; Oliveira et al., 2018; Sadeghi, 2019)

\begin{tabular}{lll}
\hline & Advantages & Disadvantages \\
\hline students & $\begin{array}{l}\text { flexibility, availability, low } \\
\text { cost, time and space } \\
\text { independent, no } \\
\text { commuting }\end{array}$ & $\begin{array}{l}\text { danger of distraction, self-discipline necessary, } \\
\text { no immediate instructor feedback, technical } \\
\text { difficulties }\end{array}$ \\
$\begin{array}{l}\text { educational } \\
\text { institutions }\end{array}$ & $\begin{array}{l}\text { lower cost, no need for } \\
\text { physical space, reuse }\end{array}$ & $\begin{array}{l}\text { drop-out rates, investment costs, difficult to } \\
\text { reach and engage students, difficult to } \\
\text { incorporate applied activities, cultural aspects, } \\
\text { acceptance of online qualification }\end{array}$ \\
\hline
\end{tabular}




\section{Method}

This paper reports the experience and findings from the iterative development and implementation of a digital leadership course for SME. In addition to the challenges of providing SME training, the course had to be delivered virtually due to the COVID-19 pandemic. The aim of our research was to systematically design the course and report the findings and identify learnings for the time after the pandemic. We studied the following research question:

- How can virtual learning be used to create a responsive learning environment in leadership training for SME?

The study was connected to the need to solve an actual practical aim. In context of this aim, the participating researchers took an active role of course designers and instructors. Given the responsive nature of the course, the participating learners also actively influenced the design. Therefore, action research was chosen as a suitable approach (Banegas \& Consoli, 2020). This method allows a systematic process of inquiry where the researcher monitors and reflects on actions taken in a development or a change process using data-driven analysis to guide subsequent actions, aiming at finding effective solutions to everyday problems and improving the outcomes; the process is iterative and includes several Look-Think-Act spiral loops (Maestrini et al., 2016; Stringer, 2014).

\section{Course in digital leadership}

The course for digital leadership has been specifically developed for SME managers to support the digitalisation in SMEs in Austria. The needs of SME often differ from those of large enterprises (different context, seriously limited resources, and specific and niche markets); therefore, commonly available training might fail to provide them with actionable input. Furthermore, their size and structure vary considerably. Extensive continuing education programs in the area of digitalization, innovation or digital business transformation are available for corporate managers. However, these are either too specific, too technical, or too theoretical and require a large time investment, which is a challenge for SME managers. Many SMEs are centrally managed by their owners, so the attitude of the management is crucial for the adoption of new technologies and operating models. In order to effectively address the concerns of SME leadership regarding upskilling, the IMC FH Krems developed a new type of management mini-course in the area of continuing education as part of Digital Innovation Hub Ost project. The goal was to increase the innovation and digitization competencies of SME executives in the area of management and leadership, and to clearly stand out from conventional offerings (no frontal teaching, little theory, focus on identifying and solving problems collaboratively). 


\section{Course design principle l: Adaptive learning}

Kayes (2002) addresses the role of experience in management learning and education by reviewing Kolb's experiential learning theory. In his article, Kayes recognizes four general approaches in management learning: (a) action (action-based learning to drive behavioural changes when solving organizational problems), (b) cognition (influencing thinking, e.g. memory, mental models and schemas), (c) reflection (encouraging reflection on assumptions and beliefs), and finally (d) experience (specifically experiencing positive emotions and feelings, recognizing learners as human beings who need not only to nourish their minds, but also their hearts and souls).

Our proposed education model, designated as Adaptive Lean Learning (ALL), was based on the principles of agile development and delivery as shown in Figure 1. It built on the experiential learning theory focusing on personalised, problem-based, effective and efficient learning. According to lean principles, the learners should cover only what is relevant for them, losing no time through superfluous content and generating no waste.

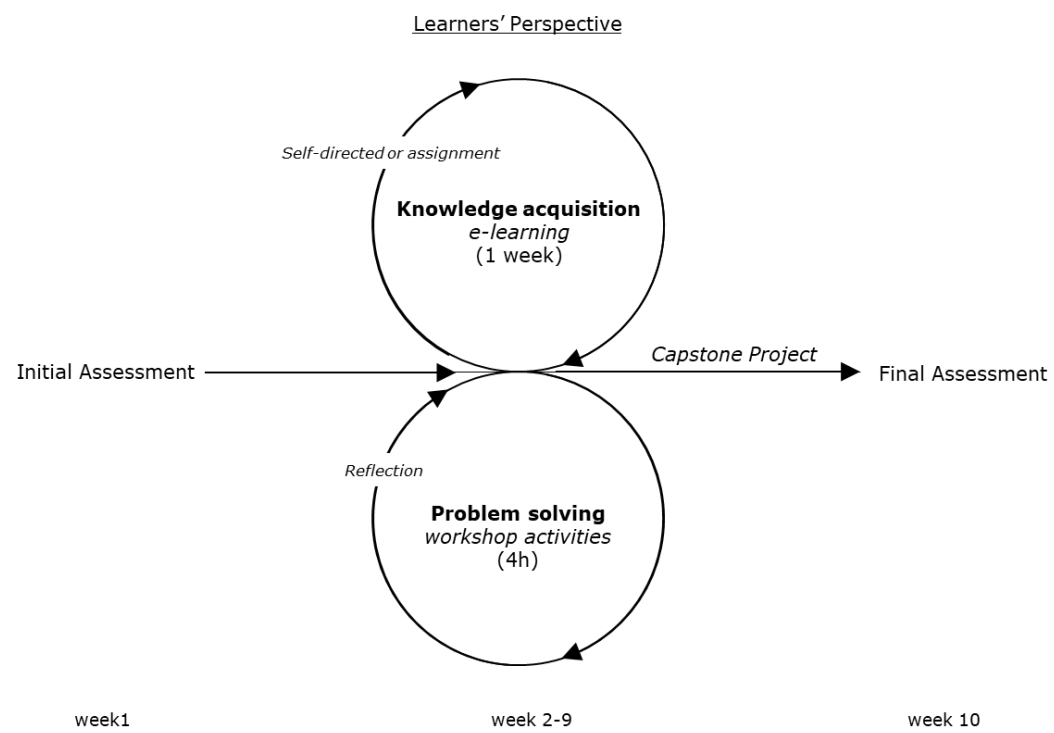

Figure 1. Adaptive Lean Learning Model: Learners' Perspective

The course consisted of 10 weekly workshops (4h each, on Tuesday afternoons), spanning a period of 3 months. Two weeks before the start, all registered participants received an online survey questionnaire concerning personal, professional and demographic information about them and their companies. Each week, the participants would attend an online workshop addressing a certain topic, contributing their own experiences and challenges. The trainers acted as a facilitators and coaches, inviting everyone to solve specific business problems. At the end of each workshop session, a reflection and discussion round were held where the participants reflected on what and how they have learned and gave feedback about the session. This corresponds to the lower loop in Figure 1 designated as "Problem solving". Between the sessions, the participants would acquire 
any missing knowledge or deepen their existing knowledge by either engaging in selfdirected learning or fulfilling assignments given by the trainer, using an online e-learning tool for digital transformation for SMEs available on the web. This corresponds to the upper loop in Figure 1 designated "Knowledge acquisition". The process of passing through the double loop was repeated eight times during eight weeks, culminating in a capstone project presented by each participant in the last session. The last session also included a final assessment survey, as well as a 33-multiple-choice knowledge assessment quiz emulating the written exam needed for the P53 Digital Officer certification.

\section{Course design principle II: Responsive teaching}

This course targeted managing directors, business owners, or non-technical first line managers with over 10 years managerial experience working in SMEs. The pilot run was limited to 7 participants (see Table 2).

Table 2: $\quad$ Participants in the pilot course November 2020 to January 2021

\begin{tabular}{llllcl}
\hline Participant & Gender & Education & Role & Company size & Industry segment \\
\hline P1 & F & secondary & Manager & $10-49$ & Food \& beverage \\
& & & & & manufacturing \\
P2 & F & tertiary & Business owner & $1-9$ & Marketing \\
P3 & F & tertiary & Manager & $1-9$ & Consulting \\
P4 & M & secondary & Manager & $10-49$ & Conference operator \\
P5 & M & tertiary & Business owner & $50-99$ & Food \& beverage \\
& & & & & manufacturing \\
P6 & M & tertiary & Manager & $100-250$ & Electrical engineering \\
P7 & M & secondary & Business owner & 1 & Electrical engineering \\
\hline
\end{tabular}

Because little was known about the knowledge gaps and skill-needs of SME managers, we used the initial survey to assess the individual competencies and expectations as well as personal and corporate challenges of the participants. This information was used to prepare a tentative high-level curriculum and plan the first workshop. 


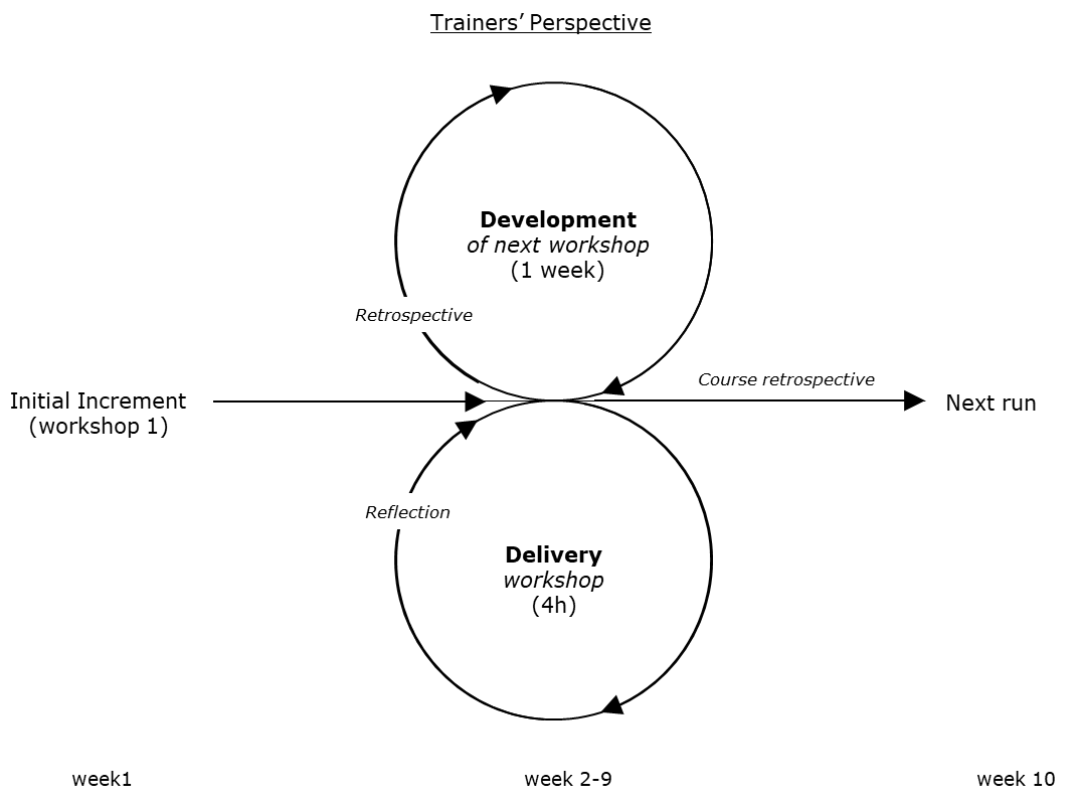

Figure 2. Adaptive Lean Learning Model: Trainers' Perspective

The course relied on a continuous, iterative process depicted in Figure 2, interweaving development and delivery along eight sprints. At the end of each delivery sprint or workshop, the participants gave feedback in a reflection session that would serve as an input for developing the next workshop during the subsequent development sprint. This double-loop (double-sprint) cycle was repeated until the last session. We did not use the exact artefact definitions of agile methods, but applied the principles as we deemed suitable for our special needs.

\section{Learning in virtual environment}

Initially, the course was to be delivered in a hybrid format, the first and the last sessions of the course being held on-site at the IMC in Krems, all remaining sessions being held virtually. Due to strict COVID-19 restrictions during November 2020, the whole course became virtual. Virtual courses are unusual in context of the target group, but in the given situation, the participants were open to the virtual format.

\section{Course structure}

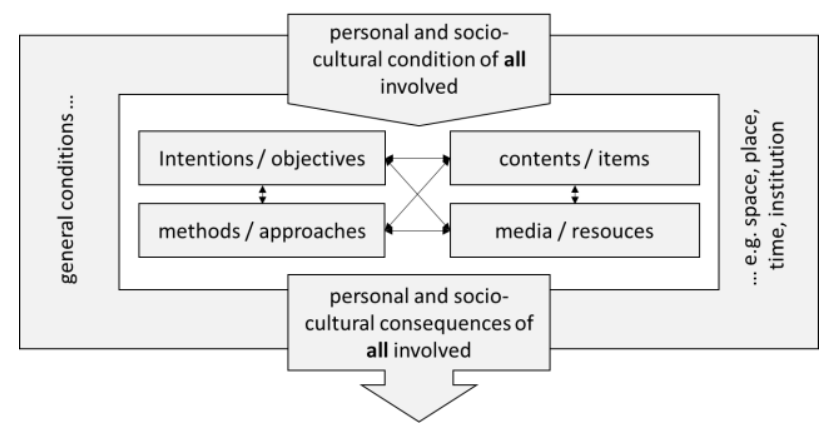

Figure 3. Didactical model of the course (based on the "Berlin Model", Heimann, 1979; Zierer et al., 2018) 
The didactical model of the course was based on the Berlin Model, and alignment between the six factors was sought starting with the intentions and objectives. The primary course intentions and objectives are summarized in Table 3 . The specific learning goals were to equip the participants with (a) an open mindset for growth including managerial ambidexterity, agility and adaptability, (b) a skillset comprising of the four key digital competencies, namely understanding digital trends and technologies and their application in business, business process optimization and automation, business model innovation and implementing change, and (c) a useful toolset comprising management models and frameworks like PESTEL, SWOT, 7S, Business Model Canvas as well as productivityenhancing virtual communication and collaboration tools such as communication platform Microsoft Teams and the whiteboard Miro. A secondary objective was to prepare the participants for the personal competence certification of the Austrian Standards' P53 certification scheme "Digital Officer", which is carried out in accordance with the International ISO/IEC 1702 standard. The certification requirements include attending a 40-hour course covering the areas of Digital Technologies, Data \& Information Security, Digital Marketing and Digital Strategies and Business Models, which also influenced the contents of the course.

Table 3: $\quad$ Primary course objectives (equipping participants with...)

\begin{tabular}{lll}
\hline Mindset & Skillset & Toolset \\
\hline Ambidexterity & Digital Technologies & Management Frameworks \\
Agility & Business Processes & Collaboration Software \\
Adaptability & Business Models & \\
& Change Management & \\
\hline
\end{tabular}

The methods and approaches were based on the previously elaborated experiential learning theory. The media and resources were what distinguished this course from traditional courses or trainings for SME managers. These were exclusively web-based and consisted of e-learning content, virtual communication via Microsoft Teams, and a collaboration tool through Miro, defining the general conditions of the Berlin Model, namely space and place.

\section{Findings and discussion}

The pilot run of the digital leadership course was evaluated by analysing the final survey and comparing it with the initial survey using descriptive and inferential statistics. A simplified self-reported scale was used to measure the digital competency based on DigComp 2.2 AT (Swertz, 2019) and the managerial ambidexterity was measured using a scale introduced by Mom et al. (2009). Due to the small number of participants, inferences could only be made to a significance level of $\alpha=0.08$ (see Table 4). 
Hage, R., Lovasz-Bukvova, H., Hopp, M., Hölzl, M., Kormann-Hainzl, G., Reiner, M., \& Dhungana, D.

Agile Approach for E-Learning in Digital-Leadership Training for Small and Medium Enterprises

Table 4: $\quad$ Course evaluation results $(n=6)(n=7)$

\begin{tabular}{|c|c|c|c|c|}
\hline Measure & Before & After & Difference & Remark \\
\hline Expectation fulfilment & & $86 \%$ & & $\begin{array}{l}6 \text { out of } 7 \text { said their expectations } \\
\text { were met }\end{array}$ \\
\hline Net Promoter Score (NPS) & & -29 & & 1 promoter, 3 passives, 3 detractors \\
\hline Managerial ambidexterity & 2.34 & 2.13 & $-9 \%$ & $\begin{array}{l}\text { Scale } 1 \text { to } 7(p=0.77)^{*} \text { No significant } \\
\text { change! }\end{array}$ \\
\hline Familiarity with technology & 3.81 & 4.57 & $+20 \%$ & Scale 1 to $7(p=0.08)^{*}$ \\
\hline Digital competence & 2.14 & 2.94 & $+38 \%$ & Scale 1 to $4(p=0.06)^{*}$ \\
\hline Knowledge assessment & & $60 \%$ & & $\begin{array}{l}3 \text { from } 5 \text { passed the quiz } \\
\text { (grade }>60 \% \text { ) }\end{array}$ \\
\hline $\begin{array}{l}\text { Willingness to get certified } \\
\text { (P53) }\end{array}$ & & $70 \%$ & & $\begin{array}{l}5 \text { from } 7 \text { indicated that they will } \\
\text { apply for P53 }\end{array}$ \\
\hline
\end{tabular}

* a paired Student's t-test for the differences in scores after versus before was performed and the corresponding $\mathrm{p}$-value is reported in the table

Among other points, the participants were asked what they liked most. More than $50 \%$ of the answers were related to the virtual character of the course, e.g. "the format despite Covid", "the e-learning and the quiz at the end", "Tools", "Tools for approaching and planning digitization projects (e.g. Miro)”, which further confirmed the suitability of the online and virtual format of the course.

\section{Conclusions}

The findings show a general acceptance for the virtual format of the course. At the same time the disadvantage of such a $100 \%$ virtual course was that the on-site introduction session was skipped, which resulted in excessive efforts in training the participants to use virtual communication tools (MS Teams) for the first time, in a virtual setting (is a paradox in itself). Another disadvantage was the lack of the opportunity to build trust and rapport with the trainers, as well as socializing with peers, which normally takes place via face-toface introductions and informal small talk. The presented Agile Lean Learning (ALL) model allowed a continuous development and delivery of the course in a responsive and adaptive manner, which was an ideal way to reduce uncertainty due to the heterogeneity of the participants as well as the unpredictability of the implications of the COVID-19 pandemic. The pilot run increased the digital competence of the participants by $38 \%$ $(p=0.06)$. The expectations of the participants were fulfilled, but apparently the pilot was not attractive enough to achieve a positive Net Promoter Score (NPS). The learnings from the pilot will be implemented in the next run starting April 2021, which will be carried out in a similar agile way. 


\section{References}

Ates, A., Garengo, P., Cocca, P., \& Bititci, U. (2013). The development of SME managerial practice for effective performance management. Journal of Small Business and Enterprise Development, 20(1), 28-54. https://doi.org/10.1108/14626001311298402

Bager, T. E., Jensen, K. W., Nielsen, P. S., \& Larsen, T. A. (2015). Enrollment of SME managers to growth-oriented training programs. International Journal of Entrepreneurial Behavior \& Research, 21(4), 578-599. https://doi.org/10.1108/IJEBR12-2014-0224

Banegas, D. L., \& Consoli, S. (2020). Action research in language education. In J. McKinley \& H. Rose (Eds.), The Routledge Handbook of Research Methods in Applied Linguistics (pp. 176-187).

Dumford, A. D., \& Miller, A. L. (2018). Online learning in higher education: Exploring advantages and disadvantages for engagement. Journal of Computing in Higher Education, 30(3), 452-465. https://doi.org/10.1007/s12528-018-9179-z

Heimann, P. 1901-1967. (1979). Unterricht: Analyse und Planung (10., unveränd. Aufl.). Schroedel.

Johnston, K., \& Loader, K. (2003). Encouraging SME participation in training: Identifying practical approaches. Journal of European Industrial Training, 27(6), 273-280. https://doi.org/10.1108/03090590310479901

Jones, P., Beynon, M. J., Pickernell, D., \& Packham, G. (2013). Evaluating the Impact of Different Training Methods on SME Business Performance. Environment and Planning C: Government and Policy, 31(1), 56-81. https://doi.org/10.1068/c12113b

Kayes, D. C. (2002). Experiential Learning and Its Critics: Preserving the Role of Experience in Management Learning and Education. Academy of Management Learning \& Education, 1(2), 137-149. https://doi.org/10.5465/amle.2002.8509336

Li, K. C., \& Wong, B. T.-M. (2019). How Learning Has Been Personalised: A Review of Literature from 2009 to 2018. In S. K. S. Cheung, L.-K. Lee, I. Simonova, T. Kozel, \& L.-F. Kwok (Eds.), Blended Learning: Educational Innovation for Personalized Learning (pp. 72-81). Springer International Publishing. https://doi.org/10.1007/9783-030-21562-0_6

Maestrini, V., Luzzini, D., Shani, A. B. (Rami), \& Canterino, F. (2016). The action research cycle reloaded: Conducting action research across buyer-supplier relationships. Journal of Purchasing and Supply Management, 22(4), 289-298. https://doi.org/10.1016/j.pursup.2016.06.002 
Mom, T. J. M., van den Bosch, F. A. J., \& Volberda, H. W. (2009). Understanding Variation in Managers' Ambidexterity: Investigating Direct and Interaction Effects of Formal Structural and Personal Coordination Mechanisms. Organization Science, 20(4), 812-828. https://doi.org/10.1287/orsc.1090.0427

Oliveira, M. M. S. de, Penedo, A. S. T., \& Pereira, V. S. (2018). Distance education: Advantages and disadvantages of the point of view of education and society. Dialogia, O(29), 139-152. https://doi.org/10.5585/dialogia.N29.7661

Parsons, D., \& MacCallum, K. (2019). Agile Education, Lean Learning. In D. Parsons \& K. MacCallum (Eds.), Agile and Lean Concepts for Teaching and Learning: Bringing Methodologies from Industry to the Classroom (pp. 3-23). Springer. https://doi.org/10.1007/978-981-13-2751-3_1

Prain, V., Cox, P., Deed, C., Dorman, J., Edwards, D., Farrelly, C., Keeffe, M., Lovejoy, V., Mow, L., Sellings, P., Waldrip, B., \& Yager, Z. (2012). Personalised learning: Lessons to be learnt. British Educational Research Journal, 39(4), 654-676. https://doi.org/10.1080/01411926.2012.669747

Sadeghi, M. (2019). A Shift from Classroom to Distance Learning: Advantages and Limitations. International Journal of Research in English Education, 4(1), 80-88. https://doi.org/10.29252/ijree.4.1.80

Stringer, E. (2014). Action research ( $4^{\text {th }}$ ed.). Sage Publications.

Swertz, C. (2019). DigComp 2.2 AT.: Hintergründe und Kontexte. Medienimpulse, 57(1), Article 1. https://doi.org/10.21243/mi-01-19-14

Zierer, K., Matanovic, I., Werner, J., \& Wernke, S. (2018). Ratings of usability of didactic models: A comparative case study in Croatia and Germany. Journal of Curriculum Studies, 50(4), 535-559. https://doi.org/10.1080/00220272.2018.1461933 